\title{
PEMANFAATAN METODE BIAYA VOLUME LABA SEBAGAI ALAT BANTU PERENCANAAN LABA PADA TAHU BAXO IBU PUDJI TAHUN 2017
}

\author{
Frizka Dhika Aprilianti, Hartono \\ Politeknik Negeri Semarang. Jl. Prof. Soedarto,S.H, Tembalang, \\ Semarang 50275
}

\begin{abstract}
The purpose of this research are to calculate the profit planning of TahuBaxoIbuPudjiin 2017 and the influence of cost mutation to profit mutation. Analytics cost of profit volume is the equipment that useful for planning and creating a decision especially the relation between cost, volume and profit. Method that used to accumulate the data is interview method and literature review. Whereas the data that used is quantitative in the form selling price, cost data and selling in 2016 then the qualitative data is general description of the company. The writing method used is description method and exposition method. The final calculation used cost profit volume method is shown that planning of profit for 2017 is Rp 244.811 .327 with sales of boiled Tahubaxo is 1.065.451 units and 451.637 units of fried Tahubaxo. Decreasing of sales income $6 \%$ will affected loss Rp 60.991 .902 and increasing of sales price 6\% will gain profit from $R p$ 244.811.166 to $R p$ 550.614.234. Mutation of variabel cost 5\% will affected decreasing of profit fromRp 244.811 .327 to $R p$ 55.679.045 (increase) or increasing become $R p 433.943 .287$ (decrease). In case of change simultaneously $6 \%$ sales price and $5 \%$ variable cost will affected profit decrease from $R p 244.811 .166$ to $R p$ 128.140.219 (decrease) or increasing become $R p$ 361.482.113 (increase). Then every change one rupiah of fixed costs will change profit Rp 5,24.
\end{abstract}

Keywords : Costs, Volume, Profit, Profit Planning

\begin{abstract}
Abstrak: Tujuan penelitian ini adalah untuk menghitung perencanaan laba Tahu BaxoIbu Pudji tahun 2017 dan pengaruh mutasi biaya terhadap mutasi keuntungan. Analisis biaya volume laba adalah peralatan yang berguna untuk perencanaan dan pembuatan keputusan terutama hubungan antara biaya, volume dan keuntungan. Metode yang digunakan untuk mengumpulkan data adalah metode wawancara dan tinjauan pustaka. Sedangkan data yang digunakan adalah kuantitatif berupa harga jual, data biaya dan penjualan pada tahun 2016 dan data kualitatif adalah gambaran umum perusahaan. Metode penulisan yang digunakan adalah metode deskripsi dan metode eksposisi. Perhitungan akhir menggunakan metode biaya volume laba menunjukkan bahwa perencanaan keuntungan untuk tahun 2017 adalah Rp 244.811.327 dengan penjualan Tahu baxo rebus adalah 1.065.451 unit dan Tahu baxo goreng 451.637 unit. Penurunan pendapatan penjualan 6\% akan mempengaruhi kerugian Rp 60.991.902 dan kenaikan harga jual 6\% akan mendapatkan keuntungan dari $\mathrm{Rp}$ 244.811.166 menjadi $\mathrm{Rp}$ 550.614.234. Mutasi biaya variabel 5\% akan mempengaruhi penurunan laba dari $\mathrm{Rp} 244.811 .327$ menjadi $\mathrm{Rp} 55.679 .045$ (kenaikan) atau meningkat menjadi $\mathrm{Rp} 433.943 .287$ (penurunan). Jika terjadi perubahan secara bersamaan harga jual $6 \%$ dan biaya variabel $5 \%$ akan mempengaruhi penurunan laba dari $\mathrm{Rp} 244.811 .166$ menjadi $\mathrm{Rp}$ 128.140.219 (penurunan) atau meningkat menjadi $\mathrm{Rp} 361.482 .113$ (kenaikan). setiap perubahan satu rupiah biaya tetap akan berubah keuntungan $\mathrm{Rp} 5,24$. Kata kunci: Biaya, Volume, Laba, Perencanaan Laba
\end{abstract}




\section{PENDAHULUAN \\ Latar Belakang}

Dalam sebuah perusahaan, yang menjadi tujuan utama adalah memperoleh laba yang optimal sebagai sumber pembiayaan bagi kelangsungan hidup perusahaan. Maka dari itu, diperlukan adanya suatu cara yang tepat, sistematis dan dapat dipertanggungjawabkan untuk mencapai tujuan dari perusahaan. Manajemen harus menyusun sistem perencanaan, koordinasi dan pengendalian yang matang mengenai kegiatan yang akan dilakukan pada waktu yang akan datang.

Perencanaan adalah salah satu faktor yang sangat penting bagi perusahaan untuk mencapai tujuannya. Menurut Munandar (2007: 2), ada beberapa alasan yang mengharuskan sebuah perusahaan menyusun rencana untuk menghadapi masa yang akan datang, antara lain: masa yang akan datang penuh dengan berbagai ketidakpastian, masa yang akan datang penuh dengan berbagai alternatif pilihan yang mau tidak mau perusahaan harus memilih, rencana diperlukan oleh perusahaan sebagai pedoman kerja bagi karyawan, rencana diperlukan oleh perusahaan sebagai alat pengkoordinasian bagi seluruh kegiatan dari seluruh bagian yang ada dalam perusahaan dan rencana diperlukan oleh perusahaan sebagai alat evaluasi (pengawasan) kerja pada karyawan.

Untuk tujuan perencanaan, manajemen harus memisahkan biaya semi variabel menjadi biaya tetap dan biaya variabel agar dapat diketahui besarnya perubahan biaya tetap dan biaya variabel yang selanjutnya dapat digunakan sebagai perencanaan laba. Analisis biaya volume laba atau yang sering disebut dengan Cost-VolumeProfit Analysis (CVP Analysis) dapat dimanfaatkan oleh manajemen sebagai bahan pertimbangan untuk mengambil keputusan operasional dan strategis seperti perencanaan laba agar perusahaan dapat terhindar dari kerugian, karena perolehan laba dipengaruhi oleh tiga faktor, yaitu volume produksi, harga jual dan biaya.

Siregar et. al. (2013: 317) menyatakan bahwa "Analisis biaya volume laba (Analisis BVL) yang sering kali disebut sebagai CostVolume-Profit Analysis (CVP Analysis) merupakan alat yang berguna untuk perencanaan dan pembuatan keputusan". Analisis biaya volume laba merupakan metode yang dapat digunakan untuk mengetahui hubungan timbal balik dari volume pada biaya variabel dan biaya tetap perusahaan, pendapatan dan laba guna perencanaan dan pengambilan keputusan di masa yang akan datang. Banyak manfaat yang dapat diperoleh dari analisis biaya volume laba (BVL), diantaranya yaitu: dapat mengetahui hubungan timbal balik antara harga, volume penjualan, biaya tetap, biaya variabel serta margin kontribusi. Dari penggunaan analisis biaya volume laba (BVL), manajemen dapat mengetahui titik impas/ Break Even Point (BEP), batas keamanan/ Margin of Safety (MoS), MoS Ratio serta tingkat leverage operasi (Degree of Operating). Bagi perusahaan yang menghasilkan lebih dari satu produk, analisis biaya volume laba (BVL) juga dapat dimanfaatkan untuk menentukan bauran produk terbaik agar dapat mendapatkan laba yang diinginkan.

Pada tahun 1995, Ibu Sri Lestari Pudjijanto mulai memproduksi makanan Tahu Bakso dengan menggunakan alat seadanya dan modal tidak lebih dari Rp. 50.000,Setelah produksi selama 9 bulan, pada tahun 1996 tahu bakso tersebut diberi merek TAHUBAXO KEPODANG (karena diproduksi di Jl. Kepodang). Tahun 1999, melalui Dinas Koperasi Kabupaten Semarang dengan mengajukan permohonan dan melampirkan persyaratan yang diperlukan sebagai Perusahaan/ Industri (SIUP, TDP. TDI dll) diperoleh bantuan pinjaman modal dari PT ASABRI sebesar Rp. 5.000.000,-, yang kemudian dipergunakan untuk menambah 
modal kerja dan melengkapi sarana produksi dan pemasaran.

Pada tahun 2001 usaha semakin berkembang kemudian Ibu Pudji membangun sebuah rumah tinggal sekaligus untuk produksi di Jl.Kutilang Raya $56 \quad$ Ungaran Kabupaten Semarang. Dengan kepindahan itu maka nama merek dagang yang sebelumnya "TAHUBAXO KEPODANG" diganti dengan merek "Tahu Baxo Ibu

Pudji”. Seiring dengan berjalannya waktu, usaha yang dijalankan oleh Sri Lestari

Pudjijanto ini berkembang menjadi sebuah CV, yaitu CV Berkah. Tahun 2005, sehubungan dengan perkembangan kebutuhan bahan baku (tahu) yang terus bertambah, maka agar tidak ada ketergantungan bahan baku Pudjijanto mendirikan Pabrik Tahu di Ds. Kalisidi Kecamatan Ungaran Barat. Tahun 2007 dalam rangka meningkatkan pelayanan serta memudahkan para pelanggan/ pembeli untuk mengaksesnya khusunya yang diluar kota, dibukalah beberapa Gerai/Toko Tahu Baxo Ibu Pudji.

Tahu Baxo Ibu Pudji menjual produk antara lain yaitu Tahubaxo rebus, Tahubaxo goreng, Tahubaxo kecil, bakso aziziah, bandeng presto, bandeng otak-otak, nugget dan rolade. Dalam mejalankan usahanya, Tahu Baxo Ibu Pudji belum pernah membuat perencanaan laba secara detail dan teratur serta belum pernah merencanakan berapa banyak jumlah penjualan yang harus dicapai pada periode berikutnya agar memperoleh laba sesuai dengan yang diinginkan. Hal tersebut menjelaskan bahwa Tahu Baxo Ibu Pudji juga belum menerapkan metode biaya volume laba untuk merencanakan laba tahun selanjutnya. Dengan demikian, dapat disimpulkan bahwa kemungkinan berubahnya harga dari suatu variabel yang dapat mempengaruhi target laba juga tidak diperhitungkan.

\section{Rumusan Masalah}

Dalam menjalankan usahanya, Tahu Baxo Ibu Pudji belum pernah membuat perencanaan laba secara detail dan teratur serta belum pernah merencanakan berapa banyak jumlah penjualan yang harus dicapai pada periode berikutnya agar memperoleh laba sesuai dengan yang diinginkan. Hal tersebut menjelaskan, bahwa Tahu Baxo Ibu Pudji juga belum menerapkan metode biaya volume laba untuk merencanakan laba. Tahu Baxo Ibu Pudji menjual produk antara lain yaitu Tahubaxo rebus, Tahubaxo goreng, Tahubaxo kecil, bakso aziziah, bandeng presto, bandeng otak-otak, nugget dan rolade. Dalam penelitian peneliti membatasi masalah hanya pada tahu baxo rebus dan tahu baxo goreng, ini dikarenakan oleh tahu baxo rebus dan tahu baxo goreng memiliki prosentase penjualan yang paling tinggi.

Berdasarkan latar belakang masalah dan uraian di atas, permasalahan yang dapat dirumuskan adalah sebagai berikut:

1. Bagaimana perencanaan laba dengan menggunakan metode biaya volume laba yang akan diperoleh TAHU BAXO IBU PUDJI pada tahun 2017?

2. Bagaimana pengaruh perubahan biaya terhadap perubahan laba pada TAHU BAXO IBU PUDJI?

\section{METODE ANALISIS DATA}

Widi (2010: 253) mengatakan bahwa, "Analisis data adalah proses penghimpunan atau pengumpulan, pemodelan dan transformasi data dengan tujuan untuk menyoroti dan memperoleh informasi yang bermanfaat, memberikan saran, kesimpulan dan mendukung pembuatan keputusan". Berikut ini merupakan tahapan yang akan dilakukan dalam menganalisis data:
a. Penggolongan biaya;
b. Pemisahan biaya semivariabel menjadi biaya tetap dan biaya variabel ;
c. Penghitungan Margin Kontribusi dan Rasio Margin Kontribusi;


d. Analisis Break Even Point;

e. Penghitungan Margin of Safety;

f. Perhitungan Operating Leverage;

g. Perencanaan Laba tahun 2017;

h. Analisis Sensitivitas.

Tahu Baxo Ibu Pudji merupakan usaha yang tergolong Usaha Menengah yang bergerak dalam industry pengolahan pangan.Produk yang dihasilkan oleh Tahu Baxo Ibu Pudji antara lain yaitu Tahubaxo goreng, Tahubaxo rebus, Tahubaxo kecil, bakso aziziah, bandeng otak-otak, bandeng presto, nugget dan rollade.Peneliti membatasi ruang lingkup pembahasan dengan mengambil sampel produk yang memiliki prosentase penjualan tinggi.
Dari data yang terkumpul dapat diketahui, bahwa produk yang memiliki prosentase penjualan paling tinggi adalah Tahu Baxo Rebus dan Tahu Baxo Goreng. Prosentasenya yaitu sebesar $66,68 \%$ (pembulatan dari $66,57518 \%$ ) dan $28,21 \%$ (pembulatan dari 28,21468\%). Berdasarkan hal tersebut, peneliti membatasi ruang lingkup pembahasan dengan mengambil sampel produk Tahu Baxo Rebus dan Tahu Baxo Goreng. Rincian penjualan Tahubaxo Rebus dan Tahubaxo Goreng dapat dilihat pada table 1 berikut:

Tabel 1; Volume Penjualan untuk Tahubaxo Rebus dan Tahubaxo Goreng pada Tahu Baxo Ibu Pudji tahun 2016

\begin{tabular}{|l|r|r|r|r|}
\hline NAMA PRODUK & $\begin{array}{c}\text { PENJUALAN } \\
\text { (Unit) }\end{array}$ & $\begin{array}{c}\text { Harga/Unit } \\
(\mathrm{Rp})\end{array}$ & $\begin{array}{c}\text { Total Penjualan } \\
(\mathrm{Rp})\end{array}$ & $\begin{array}{c}\text { \% Penj. } \\
\text { Terhadap } \\
\text { Total Penj. }\end{array}$ \\
\hline Tahu Baxo Rebus & 1.039 .630 & 3.300 & 3.430 .779 .000 & $66,58 \%$ \\
\hline Tahu Baxo Goreng & 440.597 & 3.500 & 1.542 .089 .500 & $28,21 \%$ \\
\hline Jumlah & $\mathbf{1 . 4 8 0 . 2 2 7}$ & $\mathbf{6 . 8 0 0}$ & $\mathbf{4 . 9 7 2 . 8 6 8 . 5 0 0}$ & $\mathbf{9 4 , 7 9 \%}$ \\
\hline Total Penjualan & 1.561 .588 & & 34.354 .936 .000 & $100 \%$ \\
\hline
\end{tabular}

Sumber: Data Sekunder yang Diolah, 2016

\subsubsection{Perhitungan Anggaran Biaya Tahun 2017}

Data yang digunakan dalam biaya volume laba merupakan data realisasi biaya yang ada pada Tahu Baxo Ibu Pudji.Yaitu realisasi dari biaya tetap, biaya variabel dan biaya semi variabel yang telah dipisahkan menjadi biaya tetap dan biaya variabel pada tahun 2016. Semua data tersebut diolah untuk menghasilkan anggaran biaya tetap dan biaya variabel tahun 2017 .

\subsubsection{Anggaran Biaya Tetap Tahun 2017}

Dilihat dari karakteristiknya, biaya tetap memiliki jumlah total yang tetap tanpa dipengaruhi jumlah volume kegiatan tertentu. Oleh karena itu, anggaran biaya tetap untuk tahun 2017 menggunakan dasar realisasi biaya tetap tahun 2016. Biaya tetap untuk produk Tahubaxo Rebus dan Tahubaxo Goreng dihitung berdasarkan prosentase penjualan kedua produk terhadap total penjualan keseluruhan tahun 2016.

Data penjualan dan prosentase penjualan produk Tahubaxo Rebus dan Tahubaxo Goreng pada Tahu Baxo Ibu Pudji dapat dilihat pada tabel 1. Berdasarkan tabel tersebut maka prosentase penjualan Tahubaxo Rebus dan Tahubaxo Goreng untuk menghitung anggaran biaya tetap tahun 2017 adalah 94,79\%. Perhitungan anggaran biaya tetap 
tahun 2017 untuk produk Tahubaxo Rebus dan Tahubaxo Goreng dapat dilihat pada tabel 2

Dari hasil perhitungan biaya variabel untuk masing-masing produk

Tabel 2; Perhitungan Biaya Variabel Tahubaxo Rebus dan Tahubaxo Goreng per Unit

\begin{tabular}{|l|c|c|r|}
\hline \multicolumn{1}{|c|}{ Jenis Produk } & $\begin{array}{c}\text { Biaya Variabel per } \\
\text { Produk (Rp) }\end{array}$ & $\begin{array}{c}\text { Penjualan } \\
\text { (unit) }\end{array}$ & $\begin{array}{c}\text { Biaya Variabel per } \\
\text { Unit (Rp) }\end{array}$ \\
\hline Tahubaxo Rebus & 2.546 .258 .049 & 1.039 .630 & 2.449 \\
\hline Tahubaxo Goreng & 1.144 .509 .476 & 440.597 & 2.598 \\
\hline
\end{tabular}

Sumber: Data Sekunder yang Diolah, 2016

4.2.5 Perhitungan Biaya Volume Laba

Komposisi penjualan untuk produk Tahubaxo Rebus dan Tahubaxo Goreng dapat dihitung dengan membandingkan jumlah Tabel 3; Perhitungan Biaya Variabel Tahubaxo Rebus dan Tahubaxo Goreng

\begin{tabular}{|l|r|r|}
\hline \multicolumn{1}{|c|}{ Nama Produk } & Penjualan (Unit) & Komposisi Penjualan \\
\hline Tahu Baxo Rebus & 1.039 .630 & $70,23 \%$ \\
\hline Tahu Baxo Goreng & 440.597 & $29,77 \%$ \\
\hline Jumlah & 1.480 .227 & $100.00 \%$ \\
\hline
\end{tabular}

Sumber: Data Sekunder yang Diolah, 2016

4.2.5.1 Perhitungan Break Even Point

Tahun 2016

Break even point merupakan suatu keadaan dimana total penghasilan sama dengan total biaya. Sebelum menghitung break even

\section{Tabel 4}

Perhitungan Contribution Margin Tahubaxo Rebus dan Tahubaxo Goreng

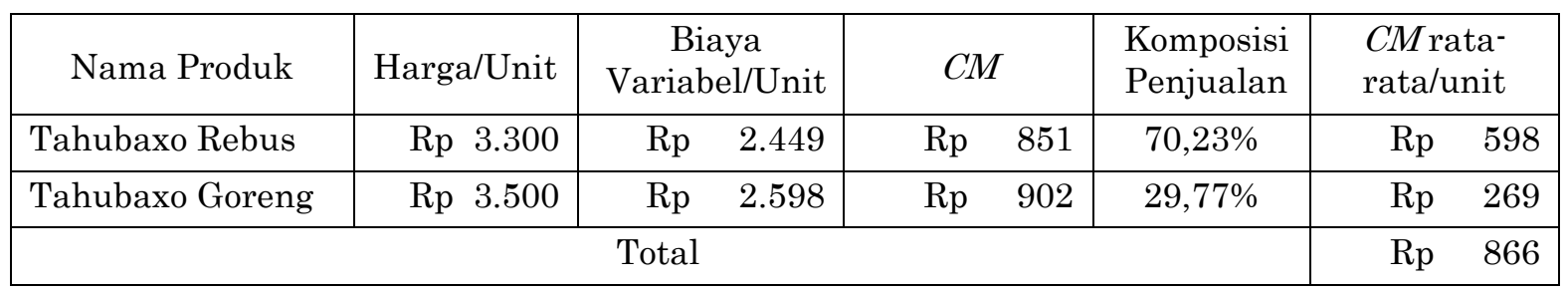

Sumber: Data Sekunder yang Diolah, 2016

Dari perhitungan contribution margin di atas maka break even point dapat diketahui, baik break even point dalam unit maupun dapan rupiah penjualan.

Dari perhitungan diatas dapat diketahui bahwa rasio penjualan terhadap margin atau yang biasa disebut dengan contribution margin ratio rata-rata pada Tahu Baxo Ibu penjualan masing-masing produk dengan total penjualan kedua produk kemudian dikalikan dengan $100 \%$. Berikut ini adalah komposisi penjualan Tahubaxo rebus dan Tahubaxo goreng tahun 2016.

point, terlebih dahulu diperlukan menghitung contribution margin.Perhitungan contribution margin dapat dilihat pada tabel 4 halaman berikut ini:

pada halaman sebelumnya, maka besarnya biaya variabel per unit produk dapat adalah sebagai berikut:

per


tersebut maka dapat dihitung BEP

dalam

rupiah.

$$
\begin{aligned}
& =\frac{\text { Total kos tetap }}{\text { CM Ratio }} \\
& =\frac{\text { Rp.1.069.264.209 }}{25,78 \%} \\
& =\operatorname{Rp} 4.147 .650 .151,9
\end{aligned}
$$

Untuk menghitung BEP dalam unit, maka dapat menggunakan rumus sebagai berikut:

Titik $\begin{gathered}\text { Impas } \\ =\end{gathered}$
$=\frac{\text { Margin kontribusi per unit } 1.069 .264 .209}{\operatorname{Rp} 866}$

$=1.234 .456$ unit

Tingkat penjualan dalam unit pada break even point untuk masingmasing produk adalah:

Tahubaxo Rebus

$$
\begin{aligned}
& =70,23 \% \times 1.234 .456 \text { ur } \\
& =866.958 \text { unit }
\end{aligned}
$$

\section{BEP (rupiah)}

Berdasarkan perhitungan diatas dapat diketahui bahwa tingkat penjualan pada titik impas untuk produk Tahubaxo Rebus danTahubaxo Goreng yaitu sebesar 1.234.456 unit dengan perincian sebesar 866.958 unit untuk Tahubaxo Rebus dan 367.498 unit untuk Tahubaxo Goreng.

2.5.2 Perhitungan Margin of Safety Tahun 2016

Margin of Safety adalah batas keamanan dimana penjualan yang dianggarkan boleh turun tetapi perusahaan tidak menderita rugi atau maksimal perusahaan dalam keadaan titik impas. Untuk menghitung margin of safety dapat dilakukan dengan cara mengurangkan total penjualan tahun

$=29,77 \% \times 1.234 .456$ un16 dengan total penjualan pada $=367.498$ unit total penjualan tahun 2016 Perhitungan margin of safety pada tahun 2016 adalah sebagai berikut:

Margin of Safety Ratio (MoS)

$$
\begin{aligned}
= & \frac{\text { penjualan dianggarkan-penjualan pada titik impas }}{\text { Penjualan dianggarkan }} \\
= & \frac{\mathrm{Rp} 4.972 .868 .500-\mathrm{R} .4 .147 .650 .152}{\mathrm{Rp} 4.972 .868 .500} \\
& =0,16603(16,60 \%) \\
& =16,60 \% \times \mathrm{Rp} 4.972 .868 .500 \\
& =\mathrm{Rp} 825.496 .171
\end{aligned}
$$$$
\text { Margin of Safety (Rupiah) } \quad=16,60 \% \times \text { Rp } 4.972 .868 .500
$$

Dilihat dari hasil perhitungan di atas, dapat diketahui bahwa penjualan dapat turun maksimal sebesar $16,60 \%$ atau $\mathrm{Rp} 825.496 .171$ sebelum perusahaan mencapai titik impas.
4.2.5.3Perhitungan
Operating Leverage
Untuk mengukur besarnya penggunaan biaya tetap pada perusahaan dapat menggunakan perhitungan operating leverage. Degree of operating leverage dihitung dengan membandingkan margin kontribusi dengan laba bersih. Berikut perhitungan operating leverage pada Tahu Baxo Ibu Pudji tahun 2016:

$$
\begin{aligned}
& D O L=\frac{\text { Contribution margin }}{\text { Laba bersih }} \\
& =\frac{\operatorname{Rp} 1.282 .143 .624}{\operatorname{Rp} 212.879 .415} \\
& =\mathrm{Rp} \quad 6,02 \text { (pembulatan dari } \\
& (6,02286)
\end{aligned}
$$

Tingkat operating leverage pada Tahu Baxo Ibu Pudji pada tahun 2016 adalah $\mathrm{Rp}$ 6,02. Hal ini menunjukkan bahwa setiap perubahan satu rupiah 
biaya tetap akan merubah laba sebesar Rp 6,02.

4.2.6 Perencanaan Laba Tahun 2017

Berdasarkan informasi yang diperoleh dari Tahu Baxo Ibu Pudji, target laba yang ingin dicapai Tahu Baxo Ibu Pudji untuk tahun 2017 adalah naik sebesar $15 \%$ dari jumlah laba yang diperoleh pada tahun 2016 . Dasar dari perencanaan laba tahun 2017 yaitu menggunakan data realisasi tahun 2016 .

Unit penjualan untuk mencapai target

Berikut ini adalah komposisi masingmasing produk untuk anggaran laba

Tahubaxo Rebus

$$
=70,23 \% \times 1.517 .088 \text { unit }
$$$$
=1.065 .451 \text { unit (pembulatan dari 1.065.450,90) }
$$

Tahubaxo Goreng

$$
=29,77 \% \times 1.517 .088 \text { unit }
$$

$=451.637$ unit (pembulatan dari 451.637,1)

Dari perhitungan diatas dapat disimpulkan bahwa untuk mendapatkan laba sebesar Rp 244.811.327, maka Tahu Baxo Ibu Pudji harus dapat menjual 1.065.451 unit Tahubaxo Rebus dan 451.637 unit Tahubaxo Goreng. Hal ini dapat dibuktikan pada tabel 5 di halaman berikutnya.
4.2.7 Perhitungan Margin of Safety Tahun 2017

Dari tabel 5 dapat diketahui bahwa total anggaran penjualan untuk tahun 2017 sebesar Rp 5.096.717.800 dan tingkat penjualan pada titik impas $\mathrm{Rp} \mathrm{4.147.651.102.}$ dengan demikian maka perhitungan margin of safety untuk tahun 2017 adalah sebagai berikut:

$$
\begin{aligned}
& \text { Margin of Safety Ratio }(M o S)=\frac{\text { penjualan dianggarkan-penjualan pada titik impas }}{\text { Penjualan dianggarkan }} \\
& =\frac{\operatorname{Rp} 5.096 .717 .800-\operatorname{Rp} 4,147,650.152}{\operatorname{Rp} 5.096 .717 .800} \\
& =0,186211(18,62 \%) \\
& \text { Margin of Safety (Rupiah) } \quad=18,62 \% \text { x Rp 5.096.717.800 } \\
& =\operatorname{Rp} 949.008 .854
\end{aligned}
$$

Dari perhitungan di atas, dapat ditarik kesimpulan bahwa apabila penjualan yang dianggarkan tidak dapat tercapai maka batas penurunan penjualan maksimal adalah sebesar $18,62 \%$ atau Rp 949.008.854 sebelum mencapai titik impas.
Analisis Sensitifitas

Analisis sensitivitas merupakan analisis terhadap perubahan faktorfaktor yang dapat mempengaruhi laba. Analisis ini dapat dipakai manajemen untuk menghadapi 
berbagai kemungkinan perubahan kondisi yang dapat mempengaruhi laba perusahaan. Perubahan yang mungkin terjadi yaitu antara lain perubahan harga jual, perubahan biaya variabel per unit dan perubahan biaya tetap. Perubahan

1. Perhitungan Degree of Operating Leverage tahun 2017

Degree of operating leverage dihitung dengan membandingkan margin kontribusi dengan laba bersih.Target laba yang direncanakan pada tahun 2017 adalah Rp 244.811.327. Berikut perhitungan operating leverage pada Tahu Baxo Ibu Pudji tahun 2017:

$D O L$

$$
\begin{aligned}
& =\frac{\text { Contribution margin }}{\text { Laba bersih }} \\
& =\frac{\operatorname{Rp~1.282.143.624}}{\operatorname{Rp~244.811.327}}
\end{aligned}
$$

$=\operatorname{Rp~5,24}$ (pembulatan dari $(5,23727)$

Tingkat operating leverage pada Tahu Baxo Ibu Pudji pada tahun 2017 adalah $\mathrm{Rp}$ 5,24. Hal ini menunjukkan bahwa setiap perubahan satu rupiah biaya tersebut dapat mempengaruhi perencanaan laba. Untuk itu diperlukan analisis sensitivitas untuk mengetahui dampak dari perubahan tersebut. Berikut ini adalah analisis sensitivitas pada Tahu Baxo Ibu Pudji:

tetap akan merubah laba sebesar Rp 5,24.

2. Perubahan Harga Jual Tahubaxo Rebus dan Tahubaxo Goreng Terhadap Titik Impas, Target Laba dan Margin of Safety

Berdasarkan kebijakan perusahaan, direncanakan akan ada kenaikan harga Tahu Baxo Goreng dan Tahu Baxo Rebus. Tahu Baxo Rebus dan Tahu Baxo Goreng yang semula harganya Rp 3.300 dan Rp 3.500 per unit akan dinaikkan menjadi $\mathrm{Rp} 3.500$ dan Rp 3.700 per unit atau sebesar $6 \%$ per unit.

Perhitungan perubahan harga jual Tahubaxo Rebus dan Tahubaxo Goreng terhadap titik impas, target laba dan margin of safety pada Tahubaxo Ibu Pudji Tahun 2017 dapat dilihat pada tabel 5 pada halaman berikut:

Tabel 5; Perhitungan Perubahan Harga Jual Tahubaxo Rebus dan Tahubaxo Goreng Terhadap Titik Impas, Target Laba dan Margin of Safetypada Tahu Baxo Ibu Pudji tahun 2017

\begin{tabular}{|l|l|c|c|c|}
\hline & \multicolumn{1}{|c|}{ Keterangan } & Penurunan & Mula-Mula & Kenaikan \\
\hline$(1)$ & Pendapatan Penjualan 6\% & 4.790 .914 .732 & 5.096 .717 .800 & 5.402 .520 .868 \\
\hline$(2)$ & Biaya Variabel & 3.782 .642 .425 & 3.782 .642 .425 & 3.782 .642 .425 \\
\hline$(3)$ & Laba Kontribusi (1) - (2) & 1.008 .272 .307 & 1.314 .075 .375 & 1.619 .878 .443 \\
\hline$(4)$ & Biaya Tetap & 1.069 .264 .209 & 1.069 .264 .209 & 1.069 .264 .209 \\
\hline$(5)$ & Laba Sasaran (3) - (4) & $(60.991 .902)$ & 244.811 .166 & 550.614 .234 \\
\hline$(6)$ & $\begin{array}{l}\text { Margin Kontribusi } \\
\text { RataRata (3) }: 1.517 .088\end{array}$ & 799 & 866 & 1.068 \\
\hline$(7)$ & $\begin{array}{l}\text { Rasio Margin Kontribusi } \\
(3):(1)\end{array}$ & $21,05 \%$ & $25,78 \%$ & $29,98 \%$ \\
\hline$(8)$ & $\begin{array}{l}\text { Titik Impas (Unit) }=(4): \\
(6)\end{array}$ & 1.38 .253 & 1.234 .716 & 1.001 .413 \\
\hline$(9)$ & $\begin{array}{l}\text { Titik Impas (Rupiah) }= \\
(4):(7)\end{array}$ & 5.080 .724 .340 & 4.147 .203 .449 & 3.566 .145 .489 \\
\hline
\end{tabular}




\begin{tabular}{|l|l|c|c|c|}
\hline$(10)$ & Target laba & 244.811 .327 & 244.811 .327 & 244.811 .327 \\
\hline \multicolumn{5}{|c|}{ Penjualan Saat Target Laba } \\
\hline$(11)$ & Unit (4)+(10):(6) & 1.644 .650 & 1.517 .408 & 1.230 .690 \\
\hline$(12)$ & Rp (4)+(10):(7) & 6.243 .971 .793 & 5.096 .718 .424 & 4.382 .625 .459 \\
\hline \multicolumn{5}{|c|}{ Break Even Point } \\
\hline$(13)$ & Unit & 8,39 & 0 & $-18,9$ \\
\hline$(14)$ & Rp & 22,5 & 0 & -14 \\
\hline \multicolumn{5}{|c|}{ Margin of Safety } \\
\hline$(15)$ & Unit & 306.397 & 282.692 & 229.277 \\
\hline$(16)$ & Rp & 1.163 .247 .453 & 949.514 .976 & 816.479 .970 \\
\hline$(17)$ & Ratio & $6,05 \%$ & $18,63 \%$ & $33,99 \%$ \\
\hline
\end{tabular}

Sumber: Data Sekunder yang Diolah, 2016

Berdasarkan perhitungan tabel 5 dapat diketahui, bahwa apabila harga jual Tahubaxo Rebus dan Tahubaxo Goreng mengalami penurunan sebesar 6\% akan menyebabkan kenaikan titik impas sebesar $8,39 \%$ dalam unit atau $22,5 \%$ dalam rupiah. Selain itu juga menyebabkan margin of safety meningkat, yaitu yang semula 262.692 unit menjadi 306.397 unit atau yang semula Rp 949.617.250 menjadi $\mathrm{Rp}$ 1.163.247.453.

Kenaikan harga jual sebesar 6\% akan menyebabkan penurunan titik impas sebesar 18,9\% dalam unit atau $14 \%$ dalam rupiah. Selain itu juga mengakibatkan menurunnya margin of safety dari 282.692 unit menjadi 229.277 unit atau yang semula Rp 949.617.250 menjadi Rp 816.479.970.

3. Perubahan Biaya Variabel Tahubaxo Rebus dan Tahubaxo Goreng Terhadap Titik Impas, Target Laba dan Margin of Safety

Tabel 6; Biaya Variabel Tahun 2015 dan 2016 pada Tahu Baxo Ibu Pudji

\begin{tabular}{|l|r|r|}
\hline \multicolumn{1}{|c|}{ NAMA AKUN } & \multicolumn{1}{c|}{ 2015(Rp) } & \multicolumn{1}{c|}{ 2016 (Rp) } \\
\hline Biaya Bahan Baku \& Bahan Penolong & 2.771 .209 .284 & 3.312 .689 .385 \\
\hline Biaya Tenaga Kerja Langsung & 105.316 .351 & 136.564 .748 \\
\hline Biaya Bahan Bakar & 10.385 .100 & 14.527 .500 \\
\hline Biaya Gas & 44.489 .000 & 68.770 .000 \\
\hline Biaya Barang Habis Pakai & 231.349 .246 & 319.040 .360 \\
\hline Biaya Kardus & 16.833 .016 & 21.856 .640 \\
\hline Biaya Jasa Giling & 992.689 & 1.986 .340 \\
\hline Biaya Kerugian Produk Rusak & 19.865 .401 & 27.144 .063 \\
\hline Biaya Bahan Resto & 68.767 .271 & 90.146 .364 \\
\hline JUMLAH & 3.269 .207 .358 & 3.992 .725 .400 \\
\hline
\end{tabular}

Sumber: Data Sekunder yang Diolah, 2016

Dilihat dari tabel 6, prosentase perubahan biaya variabel dari tahun 2015 ke tahun 2016 dapat

Biaya variabel per unit 2015 diketahui dari perhitungan sebagai berikut:

$=\underline{\operatorname{Rp} 3.269 .207 .358}=\operatorname{Rp} 2.572 /$ unit 1.271 .160 unit 
Biaya variabel per unit 2016

Prosentase perubahan

Dari perhitungan di atas, maka analisis sensitivitas apabila terjadi perubahan biaya variabel sebesar $5 \%$

$$
\begin{aligned}
& =\underline{\operatorname{Rp} 3.992 .725 .400}=\operatorname{Rp} 2.697 / \text { unit } \\
& 1.480 .227 \text { unit } \\
& =\underline{(\mathrm{Rp} 2.697-\mathrm{Rp} 2.572)} \times 100 \% \\
& \text { Rp } 2.572 \\
& =4,88 \% \\
& \text { (pembulatan dari 4,88\%) dapat dilihat }
\end{aligned}
$$

\begin{tabular}{|c|c|c|c|c|}
\hline & Keterangan & Penurunan & Mula-Mula & Kenaikan \\
\hline (1) & Pendapatan Penjualan & 5.096 .717 .800 & 5.096 .717 .800 & 5.096 .717 .800 \\
\hline (2) & Biaya Variabel 5\% & 3.593 .510 .304 & 3.782 .642 .425 & 3.971 .774 .546 \\
\hline (3) & Laba Kontribusi & 1.503 .207 .496 & 1.314 .075 .375 & 1.124 .943 .254 \\
\hline (4) & Biaya Tetap & 1.069 .264 .209 & 1.069 .264 .209 & 1.069 .264 .209 \\
\hline (5) & Laba Sasaran & 433.943 .287 & 244.811 .166 & 55.679 .045 \\
\hline (6) & $\begin{array}{l}\text { Margin Kontribusi Rata- } \\
\text { Rata }\end{array}$ & 991 & 866 & 742 \\
\hline (7) & $\begin{array}{l}\text { Rasio Margin } \\
\text { Kontribusi (3) : (1) }\end{array}$ & $29,49 \%$ & $25,78 \%$ & $22,07 \%$ \\
\hline (8) & $\begin{array}{l}\text { Titik Impas (Unit) }= \\
(4):(6)\end{array}$ & 1.079 .138 & 1.234 .456 & 1.442 .000 \\
\hline (9) & $\begin{array}{l}\text { Titik Impas (Rupiah) }= \\
(4):(7)\end{array}$ & 3.625 .406 .300 & 4.147.203.449 & 4.844 .455 .850 \\
\hline (10) & Target laba & 244.811 .327 & 244.811 .327 & 244.811 .327 \\
\hline \multicolumn{5}{|c|}{ Penjualan Saat Target Laba } \\
\hline (11) & Unit (4) + (10): (6) & 1.326 .210 & 1.517 .088 & 1.772 .150 \\
\hline (12) & $\operatorname{Rp}(4)+(10):(7)$ & 4.455 .454 .215 & 5.096 .718 .424 & 5.953 .608 .907 \\
\hline \multicolumn{5}{|c|}{ Break Even Point } \\
\hline (13) & Unit & $-12,58$ & 0 & 16,81 \\
\hline (14) & $\mathrm{Rp}$ & $-12,58$ & 0 & 16,81 \\
\hline \multicolumn{5}{|c|}{ Margin of Safety } \\
\hline (15) & Unit & 247.072 & 282.632 & 330.150 \\
\hline (16) & $\mathrm{Rp}$ & 830.047 .915 & 949.514 .976 & 1.109 .153 .056 \\
\hline (17) & Ratio & $18.63 \%$ & $18.63 \%$ & $18.63 \%$ \\
\hline
\end{tabular}

Tabel 7; Perhitungan Perubahan Biaya Variabel Tahubaxo Rebus dan Tahubaxo Goreng Terhadap Titik Impas, Target Laba dan Margin of Safetypada Tahubaxo Ibu Pudji tahun 2017

Sumber: Data Sekunder yang Diolah, 2016

Berdasarkan perhitungan

Tabel 7, penurunan biaya variabel sebesar $5 \%$ dapat mengakibatkan penurunan titik impas sebesar $12,58 \%$. Selain itu juga dapat menyebabkan penurunan margin of safety, yang semula 282.632 unit menjadi 247.072 unit atau yang 
semula Rp 949.514.976 menjadi Rp 830.047.915.

Kenaikan biaya variabel sebesar 5\% akan menyebabkan kenaikan titik impas sebesar $16,81 \%$. Selain itu juga mengakibatkan kenaikan margin of safety dari 282.632 unit menjadi 330.150 unit atau yang semula $R p$ 949.514.056 menjadi Rp 1.109.153.056.

4. Perubahan Simultan Harga Jual dan Biaya Variabel Tahubaxo Rebus dan Tahubaxo Goreng Terhadap Titik Impas, Target Laba dan Margin of Safety.

Tabel 8; Perhitungan Perubahan Simultan Harga Jual dan Biaya Variabel Tahubaxo Rebus dan Tahubaxo Goreng Terhadap Titik Impas, Target Laba dan Margin of Safetypada Tahu Baxo Ibu Pudji tahun 2017

\begin{tabular}{|c|c|c|c|c|}
\hline & Keterangan & Penurunan & Mula-Mula & Kenaikan \\
\hline (1) & $\begin{array}{l}\text { Pendapatan Penjualan } \\
6 \%\end{array}$ & 4.790 .914 .732 & 5.096 .717 .800 & 5.402 .520 .868 \\
\hline (2) & Biaya Variabel 5\% & 3.593 .510 .304 & 3.782 .642 .425 & 3.971 .774 .546 \\
\hline (3) & Laba Kontribusi & 1.197 .404 .428 & 1.314 .075 .375 & 1.430 .746 .322 \\
\hline (4) & Biaya Tetap & 1.069 .264 .209 & 1.069 .264 .209 & 1.069 .264 .209 \\
\hline (5) & Laba Sasaran & 128.140 .219 & 244.811 .166 & 361.482 .113 \\
\hline (6) & $\begin{array}{l}\text { Margin Kontribusi } \\
\text { Rata-Rata }\end{array}$ & 789 & 866 & 943 \\
\hline (7) & $\begin{array}{l}\text { Rasio Margin } \\
\text { Kontribusi (3) : (1) }\end{array}$ & $24,99 \%$ & $25,78 \%$ & $26,48 \%$ \\
\hline (8) & $\begin{array}{l}\text { Titik Impas (Unit) }= \\
(4):(6)\end{array}$ & 1.354 .737 & 1.234 .456 & 1.133 .791 \\
\hline (9) & $\begin{array}{l}\text { Titik Impas (Rupiah) = } \\
(4):(7)\end{array}$ & 4.278 .215 .055 & 4.147 .203 .449 & 4.037.558.661 \\
\hline (10) & Target laba & 244.811 .327 & 244.811 .327 & 244.811 .327 \\
\hline \multicolumn{5}{|c|}{ Penjualan Saat Target Laba } \\
\hline (11) & Unit (4) + (10): (6) & 1.664 .908 & 1.517 .088 & 1.393 .376 \\
\hline (12) & $\mathrm{Rp}(4)+(10):(7)$ & 5.257 .725 .540 & 5.096 .718 .424 & 4.961 .970 .125 \\
\hline \multicolumn{5}{|c|}{ Break Even Point } \\
\hline (13) & Unit & 9,74 & 0 & $(8,15)$ \\
\hline (14) & $\mathrm{Rp}$ & 3,16 & 0 & $(2,64)$ \\
\hline \multicolumn{5}{|c|}{ Margin of Safety } \\
\hline (15) & Unit & 310.171 & 282.632 & 259.585 \\
\hline (16) & $\mathrm{Rp}$ & 979.510 .486 & 949.514 .976 & 924.411 .465 \\
\hline (17) & Ratio & $10,70 \%$ & $18,63 \%$ & $25,27 \%$ \\
\hline
\end{tabular}

Sumber: Data Sekunder yang Diolah, 2016

Berdasarkan perhitungan tabel 8, penurunan harga jual sebesar $6 \%$ dan penurunan biaya variabel sebesar $5 \%$ dapat mengakibatkan penurunan titik impas sebesar 9,74\% dalam unit atau $3,16 \%$ dalam rupiah. Selain itu juga dapat menyebabkan penurunan margin of safety, yang semula 282.632 unit menjdai 420.171 unit atau yang semula Rp 949.514.976 menjadi Rp 979.510.486.

Kenaikan harga jual sebesar $6 \%$ dan biaya variabel sebesar 5\% akan menyebabkan kenaikan titik impas sebesar 8,15\% dalam unit atau 2,64\% dalam rupiah. Selain itu juga mengakibatkan kenaikan margin of safety dari 
282.632 unit menjadi 259.585 unit atau yang semula $\mathrm{Rp}$ 949.514.976 menjadi Rp24.411.465.

\section{KESIMPULAN}

Berdasarkan hasil perhitungan dengan menggunakan metode biaya volume laba sebagai alat bantu perencanaan laba pada Tahu Baxo Ibu Pudji tahun 2017 , maka dapat disimpulkan bahwa:

a. Perencanaan laba pada Tahu Baxo Ibu Pudji untuk tahun 2017 naik sebesar $15 \%$ dari tahun 2016, yaitu sebesar $R p$ 244.811.327. Total penjualan yang harus dicapai oleh Tahu Baxo Ibu Pudji agar dapat mencapai target laba yang diinginkan yaitu sebesar $\mathrm{Rp}$ 5.096.717.800 atau sebanyak 1.517.088 unit yang terdiri dari 1.065.451 unit Tahubaxo Rebus dan 451.637 unit Tahubaxo Goreng.

b. Penurunan pendapatan penjualan sebesar $6 \%$ akan mengakibatkan kerugian sebesar Rp 60.991 .902 dan kenaikan harga jual sebesar 6\% akan menyebabkan laba meningkat dari $\mathrm{Rp}$ 244.811.166 menjadi $\mathrm{Rp}$ 550.614 .234 . Perubahan biaya variabel sebesar 5\% akan mengakibatkan perolehan laba menurun dari Rp 244.811.327 menjadi $\quad \mathrm{Rp} \quad 55.679 .045$ (kenaikan) atau meningkat menjadi $\quad \mathrm{Rp} \quad$ 433.943.287 (penurunan). Apabila terjadi perubahan simultan 6\% harga jual dan $5 \%$ biaya variabel akan mengakibatkan laba menurun dari Rp 244.811.166 menjadi $R p$ 128.140.219 (penurunan) atau meningkat menjadi $\mathrm{Rp}$ 361.482.113 (kenaikan). Sedangkan setiap perubahan satu rupiah biaya tetap akan merubah laba sebesar Rp 5,24.

\section{DAFTAR PUSTAKA}

Alek dan Achmad H.P. 2011. Bahasa Indonesia Untuk Perguruan Tinggi. Jakarta: Kencana

Bungin, Burhan. 2013. Metode Penelitian Sosial dan Ekonomi. Jakarta: Kencana Prenada Media Group

Garisson, Noreen dan Brewer. 2013. Akuntansi Manajerial. Jakarta: Salemba Empat

Jusup, Al Haryono. 2011. Dasar-Dasar Akuntansi, jilid I. Yogyakarta: STIE YKPN

Kusuma, Zulkifli dan Sulastiningsih. 2013. Akuntansi Manajemen. Yogyakarta: Kampus Fakultas Ekonomi Universitas Islam Indonesia

Munandar, M. 2007. Budgeting. Yogyakarta : BPFE

Narbuko, Cholid dan Abu Achmadi. 2003. Metode Penelitian. Jakarta: Bumi Aksara

Nazir, Moh. 2013. Metode Penelitian. Bogor: Ghalia Indonesia

Samryn. 2012. Akuntansi Manajemen: Informasi Biaya untuk Mengendalikan Aktivitas Operasi \& Investasi. Jakarta: Kencana Prenada Media Grup

Simamora, Henry. 2012. Akuntansi Manajemen Edisi III. Riau : Star Gate Publisher

\footnotetext{
Siregar, Baldric., et. al. 2013.Akuntansi Manajemen.Jakarta: Salemba Empat

Sugiri, Slamet. 2009. Akuntansi Managemen. Yogyakarta: UPP STIM YKPN
} 
Sukmadinata, Nana Syaodih. 2007. Metode Penelitian Pendidikan. Bandung: PT Remaja Rosdakarya

Widoyoko, Eko Putro. 2012. Teknik

Penyusunan Instrumen Penelitian.

Yogyakarta: Pustaka Pelaja
Widi, Restu Kartiko. 2010. Asas Metodologi Penelitian. Yogyakarta: Graha Ilmu 